\title{
HABITANDO A LEI: "PIRATARIA", STREAMING, E O REGIME DE PROPRIEDADE INTELECTUAL
}

\begin{abstract}
Andressa Nunes Soilo ${ }^{1}$
${ }^{1}$ Universidade Federal do Rio Grande do Sul (UFRGS), Porto Alegre, RS, Brasil
\end{abstract}

\section{Introdução}

Os arranjos polissêmicos que conformam o campo da propriedade intelectual permitem pensar composições de direitos, e titularidades desses direitos, como construções sociais constantemente negociadas entre múltiplos atores. Tais negociações podem ser percebidas transpondo, excedendo, o âmbito legal da autoria, a partir de atuações de sujeitos sociais convencionalmente conhecidos como "piratas" sobre o controle do acesso a bens. A "pirataria", assim, dialoga com as disposições, com a ordem e com os sentidos da propriedade intelectual.

Neste momento inicial, julgo importante estabelecer a seguinte observação: a categoria analítica "pirataria", assim como suas variações vocabulares - como as palavras "pirata", "piratas" e "piratear" -, são aqui apresentadas juntamente com o recurso gráfico das aspas. Tal eleição (política) se dá em razão de a palavra "pirataria" ser amplamente significada e compreendida segundo percepções de "poderosos para se referirem à atividade de reprodução e venda de cópias não autorizadas de mercadorias valorizadas pelos consumidores contemporâneos" (Ribeiro 2010:27).

Apresentada esta breve consideração, busco demonstrar, neste artigo, o Estado como um espaço de sentidos e formações heterogêneas no âmbito da regulação dos direitos autorais. Proponho tal reflexão com base em duas análises: a dos espaços e dos atores identificados como "piratas" que atuam de modo a criar e controlar regulações; e a do mercado dos serviços legais de 
streaming que se apresentam "fora" das tramas do controle estatal. Para esta discussão utilizo, principalmente, os conceitos de "margens" proposto por Veena Das e Deborah Poole (2004), e de "legibilidade" de James Scott (1998).

A "pirataria" e seus atores se aproximam do pensamento de Das e Poole (2004) sobre "margens". Por "margens" as autoras se referem a locais em que práticas estatais são colonizadas - ou seja, ocupadas, habitadas, transformadas - por distintos modos de regulação que não os oficiais. Essas regulações extraoficiais colonizam e atualizam regras e ideias dominantes. São pensadas pelas autoras como expressões de criatividades que possibilitam modos alternativos de habitar e de constituir o mundo. Assim, neste escrito, penso a "pirataria" como uma expressão da "margem", como uma manifestação que cria novas regulações, mas que também constitui o Estado e atualiza suas normas.

Importa salientar que ao me referir ao termo "margem" não busco reforçar estigmas históricos que recaem sobre a prática "pirata", muito associada à cópia, desapropriação e distribuição não autorizada de conteúdo. Nem sugerir que a "pirataria" se refere a situações de exclusão do aparato estatal. Pelo contrário, procuro demonstrar como tal categoria se conforma ao Estado (e suas leis) a partir de suas engrenagens.

Também busco tratar, neste escrito, das produções de instrumentos que obstaculizam a assimilação do conhecimento e do entendimento do Estado sobre práticas envolvendo mercados de plataformas de streaming de música e vídeo em sua relação com a lei. O streaming, tecnologia em destaque neste estudo, corresponde à técnica que envia a dispositivos digitais conectados à internet informações de áudio e vídeo em fluxo contínuo. A transmissão de dados se dá de modo instantâneo, diferentemente do acesso ao conteúdo proveniente do download - em que há a espera de pacotes enviados por servidores para o acesso completo ao material multimídia.

A possibilidade de incompleta ou nula absorção do Estado sobre o conhecimento das práticas e das situações dos sujeitos pode ser pensada através da ideia de Scott (1998) sobre "legibilidade". Para Scott (1998), a formação do Estado moderno tem como um de seus desafios a leitura de sua população: inteirar-se sobre a localização, a riqueza, a identidade, os modos de padronização locais, entre outras informações, seriam atividades fundamentais para a monitoração e melhor controle das sociedades. Tais vigilâncias seriam uma tentativa de o ente estatal "conseguir ler" a população que governa, e de organizá-la de modo a resgatar tributos e conter rebeliões, por exemplo. "Mapas abreviados" de práticas, localizações e costumes capazes de traduzir as manifestações dos governados foram implantados para que, gradualmente, o Estado atingisse entendimento de suas populações. 
De acordo com Scott (1998), a criação de sobrenomes, a padronização de pesos e medidas, a estandardização do discurso jurídico, a invenção da posse da terra, entre outras medidas, constituem esforços de legibilidade capazes de ensejar registros e monitorações centralizados por parte do Estado.

Contudo, o autor observou que, apesar de formadores do Estado e de sua sistematicidade, processos e práticas de legibilidade por vezes não alcançam a efetividade desejada devido a fatores como: a incapacidade dos administradores de compreender a importância das experiências e dos conhecimentos locais; a desconsideração (dos gestores) da imprevisibilidade a que estão sujeitas a natureza e a sociedade; e a desatenção destinada à espontaneidade e à informalidade criativas que permeiam a vida social, o que desencadearia um contexto de ilegibilidade, já que há uma dificuldade na leitura e na tradução das experiências pelo Estado.

Nesse contexto, é possível perceber, com base nos estudos de Scott (1998), a estandardização do acesso a produções intelectuais - representado pelo conjunto de leis que tratam da propriedade intelectual - como um esforço de legibilidade que escapa não somente ao Estado, mas também, como irei mostrar, ao mercado do streaming.

Integrando minha tese sobre as relações coprodutivas entre "pirataria" e tecnologia streaming na produção do mercado do entretenimento, este estudo tem como principal objetivo demonstrar as flexibilidades e os trânsitos que as categorias legal e ilegal apresentam para o regime de propriedade intelectual e para a circulação de conteúdo multimídia. Para isso, ao longo de três anos realizei etnografia junto aos campos da "pirataria" digital, das leis, e de serviços de streaming que apresentam como principal fim a venda de acesso/assinatura, especificamente Spotify, Netflix, Deezer, Tidal, Hulu e Amazon Prime Video. ${ }^{1}$

Em termos metodológicos, esta pesquisa se fundamenta em etnografia realizada no espaço digital da internet. Para elaboração da análise que este artigo apresenta, foram coletados dados que demonstram as interações entre o legal, o ilegal e as expressões oficiais/estatais/legais. Minhas investigações se deram, sobretudo, a partir de rastreamento digital de informações através de buscadores de conteúdo (como Google e Google Scholar); da análise de notícias, regulações e discursos que permeiam o mercado cinematográfico e fonográfico desde a popularização digital da "pirataria" no começo dos anos 2000; de análise de leis e manifestações oficiais sobre direitos autorais; e de observação das relações entre participantes de um grupo dedicado a discussões e consumo de "pirataria" na mídia social Reddit.

Não houve, nesta pesquisa, o encontro geofísico entre pesquisadora e interlocutores: os agentes, as interações observadas, os dados produzidos e o campo experienciado foram possíveis através de redes de transmissão 
de dados, provedores de acesso, url (Uniform Resource Locator), ${ }^{2}$ sites, programadores, algoritmos, hardwares, entre tantos outros agentes sociotécnicos capazes de produzir e de estabelecer mediações entre pessoas e o contexto digital.

O que proponho neste artigo é que, além de as "margens" regularem o Estado quanto ao acesso a bens e informações, o Estado também é permeado por mercados legalizados que não observam normas de propriedade intelectual. Desse modo, analisarei as dinâmicas de construção de legibilidade e ilegibilidades (Scott 1998) que se instauram entre "margens", mercado, regulações e suas relações sociotécnicas.

Para além de moldar o mercado, sustentarei que as práticas e os valores "piratas" também atuam de modo a intervir nas/junto às medidas regulatórias no campo dos direitos intelectuais, gerindo suas expressões de controle. Tal argumento será fundamentado a partir da análise de mobilizações sociais (coletivos que se organizaram especialmente no campo digital) contra a implantação e a vigência de leis e enforcements (medidas de aplicação da lei) que objetivavam o recrudescimento das limitações ao acesso "pirata".

A investigação das interações e das inspirações/influências que a "pirataria" estabelece em face do regime de propriedade intelectual é importante, pois revela a magnitude (ubíqua, moral e política) do fenômeno "pirata" na atualidade, além de indicar que os agentes que conformam esse fenômeno não apenas se autorregulam e regulam o mercado de distribuição do entretenimento, mas também controlam as expressões legais sobre tais bens.

A análise dos arranjos e das ofertas de conteúdo em que a "pirataria" atua como protagonista não deve negligenciar seus aspectos criativos, coprodutivos e conformadores das normas que a ela se opõem. Por esta razão, destacarei a prática e a moral "piratas" como gerenciadoras de legibilidades, demonstrando a inscrição de seus interesses na agenda das normas jurídicas.

Assim como os agentes "piratas", muitos atores que conformam e integram a indústria do entretenimento por meio dos serviços de streaming também se percebem não observando leis de proteção intelectual. Ao longo desta pesquisa, tal circunstância se mostrou recorrente. Os canais de busca na internet apresentavam-me diversas acusações de violações de direitos autorais contra estes serviços, muitos dos quais apresentavam discursos de combate à "pirataria". ${ }^{3}$

Experienciar a lei desviando-se de seus roteiros de formalidade e apresentar práticas ilegíveis (ao Estado) no campo da distribuição de músicas, filmes e produções correlatas parecem não ser, assim, exercícios exclusivos de quem pratica a "pirataria". Percebi que, não por acaso, 
a oferta de conteúdo está tão relacionada com as intencionalidades de ações legais/ilegais quanto a questões de ilegibilidade (Scott 1998) e incompreensão do legal/ilegal, ou seja, ininteligibilidades entre normas e serviços legais apresentam-se como mais uma expressão de ilegibilidade no campo aqui estudado.

Desse modo, entrecruzando a "margem" que produz/controla legibilidade e os serviços de streaming legalizados que produzem e apontam ilegibilidades, detenho-me a investigar as disputas que a propriedade trava por ser e para ser propriedade dentro do mercado de distribuição de entretenimento.

\section{Propriedade intelectual}

Historicamente (no Ocidente) as vantagens e os benefícios dos direitos de propriedade intelectual podem ser percebidos - desde suas primeiras manifestações no fim da Idade Média ${ }^{4}$-, enquanto definidos, orientados e proferidos, especialmente pelo segmento daqueles que detinham o poder. Assim como no período de sua criação, tais normas conservam na atualidade seu fundamento quanto à capacidade de motivar criadores a apresentar suas criações à sociedade de modo a serem compensados moralmente (através do reconhecimento de genialidade e prestígio) e comercialmente (através do recebimento de dinheiro), além de ajudar no desenvolvimento da comunidade com suas obras (Burke 2003).

Apesar dessas justificativas, o regime legal em questão necessita produzir as condições para sua própria efetividade. A obra intelectual, ao contrário das obras físicas, operam por meio da produção da escassez - já que é impossível expropriar uma ideia tornando-a reduzida, ou seja, as ideias não são bens que se reduzem quando de seu uso. Convencionalmente, os mercados asseguram o lucro por meio da produção de escassez de bens não rivais, ${ }^{5}$ impedindo o uso destes sem que uma relação contratual seja estabelecida entre o usuário e o proprietário do bem.

De modo pertinente, Sell e May (2001) apontam que, diferentemente das fontes dos bens materiais caracterizadas pela limitação, os titulares dos direitos da propriedade intelectual tiveram que construir a escassez de seus bens através de instrumentos legais - ou seja, definir o que será propriedade (definindo a escassez) e o que será de domínio público -, já que, como aponta Machado (2010), diferentemente de um bem material - que possibilita ao seu detentor seu uso exclusivo -, as ideias (bens imateriais) não possibilitam a restrição plena de seu uso, a menos que sejam mantidas em segredo. 
Em termos de importância dessas normas no contexto social e global da atualidade, é interessante apontar que o regime de propriedade intelectual corresponde a um dos pilares do atual sistema capitalista, representando significativa parcela da economia ocidental hodierna. Tal conjunto de relações legais é fundamentado por tratados internacionais, especialmente pelo Acordo TRIPS (Agreement on Trade-Related Aspects of Intellectual Property Rights), assinado no ano de 1994 com a intenção de regulamentar a propriedade intelectual dos países membros da OMC (Organização Mundial do Comércio), abrangendo cerca de 160 países.

Importante destacar o protagonismo dos Estados Unidos nesse contexto de gerenciamento da regulação internacional da propriedade intelectual. Com o crescente destaque da economia americana nas últimas décadas, especialmente no que concerne às inovações tecnológicas, muitas novas companhias emergiram na América do Norte deslocando geograficamente o papel de destaque da Europa na proteção de direitos autorais e de patentes para os Estados Unidos. Esse novo arranjo político fez com que as regulamentações e a organização da política econômica internacional fossem cada vez mais direcionadas à liderança da economia estadunidense (Sell \& May 2001).

O acordo TRIPS forneceu um quadro coercitivo no qual nações buscaram se adaptar às demandas de um acordo internacional guiado basicamente pelos interesses e pelas percepções de poucos países, em especial do território estadunidense (Liu 1994). Cardwell e Ghazalian (2012) entendem que muitos países da América Central, da América do Sul e da Ásia - principalmente os que se percebem dependentes de relações comerciais com países que exercem no plano internacional grande influência tecnológica, econômica e política -, realizaram ajustes significativos em suas regulações sobre propriedade intelectual, muito em razão do receio das sanções que poderiam decorrer de uma eventual omissão.

Nesse sentido, a observação de Leal et al. (2014) se faz adequada: conforme os autores, a propriedade intelectual não seria somente uma estrutura regulatória que define o direito de exploração do conhecimento e do trabalho criativo, "mas também um discurso que legitima as estruturas de poder que fundaram a emergente economia global do conhecimento" (Leal et al. 2014).

Leal e Souza (2010) seguem promovendo uma interessante perspectiva sobre o regime em questão, apresentando a definição desse conjunto de regulações como uma cadeia global de exploração e "um sistema elevado de proteção aos direitos dos titulares" (Leal \& Souza 2010:15) que produzem uma economia do conhecimento e da informação circunscrita a determinados atores, com e a partir de certas condições. 
Os esforços em manter tal economia do conhecimento nos moldes do regime da propriedade intelectual têm se mostrado, no entanto, um desafio (Samuelson 1990). Isto porque os arranjos de controle deste conjunto de regulamentações se mostram impotentes diante da miríade de composições sociotécnicas presentes no ciberespaço, tais como: a reprodução massiva de conteúdo protegido por direitos autorais; a variedade de meios/portais "piratas" a disponibilizarem tais conteúdos; o crescente acesso à internet no mundo; a dificuldade de identificação de agentes "piratas" por atores interessados; e até mesmo a dificuldade de identificação dos detentores dos direitos autorais na internet.

Como expressou Strathern, "os teóricos dos direitos de propriedade intelectual estão no limite de suas possibilidades conceituais. Estamos aqui no limite de uma certa linguagem" (Strathern 1999:174). Apesar das inovadoras e velozes dinâmicas sociotécnicas, as leis permaneceram, em sua essência, as mesmas, delimitando o acesso às produções a partir da justificativa do incentivo à manifestação de outros criadores e à promoção do bem social. Rebecca Giblin (2018), especialista em propriedade intelectual, percebe que

A equação dos direitos autorais mudou fundamentalmente no último século, enquanto sua estrutura fundamental permaneceu praticamente inalterada. Isso ajuda a explicar por que esse conjunto de prerrogativas faz hoje um trabalho tão ruim para atingir seus objetivos. Assistimos que os principais tratados de direitos autorais são efetivamente intransponíveis, mas isso não significa que temos que continuar regulamentando tudo exatamente da mesma forma que fazíamos no passado (Giblin 2018:395).

Mesmo não manifestando alterações em sua estrutura, nas últimas duas décadas, o campo da propriedade intelectual produziu diversas legislações, assim como medidas que garantissem a aplicação da norma (enforcements), visando reforçar a punição às práticas "piratas" e limitar a liberdade de acesso no campo cibernético. No entanto, essas medidas não se deram sem negociações de atores e simpatizantes "piratas" quanto a elas.

\section{Regulando a propriedade intelectual}

A partir dos estudos de Das e Poole (2004) e de Schuch (2015), concebo as regulações sobre as criações do intelecto como coproduzidas pelas "margens" em razão das práticas "piratas". Como buscarei demonstrar a seguir, é possível visualizar as regras destinadas ao controle da "pirataria" no 
ciberespaço como fruto de negociações e coproduções entre práticas "piratas" e regulações oficiais. Compreender a natureza heterogênea das disposições de cunho normativo permite explorar as leis de propriedade intelectual não somente como manifestações de negociações entre campos de poder, mas também como expressão de sua qualidade dialógica e maleável em face da criatividade dos atores que habitam o mundo.

Assim, abordarei a seguir, leis e enforcements significativos para o entendimento da agência "pirata" junto à produção e ao controle de normas. Meu objetivo é destacar a constituição heterogênea das regulações e a descentralização da autoridade estatal.

Tendo em vista a relevância dos Estados Unidos na normatização global do regime jurídico em questão, atenho-me às regras estadunidenses e às suas dinâmicas no que diz respeito à "pirataria". Tal eleição se dá sobretudo em razão de as leis norte-americanas terem repercussões sociais, políticas, morais e até coercitivas ${ }^{6}$ em escala global, além de servirem como referência para outros modelos legais.

As normas analisadas também se caracterizam por provocar intenso debate junto aos agentes "piratas". As regulações examinadas compreendem, temporalmente, da década de 1990 até os dias atuais. Tal recorte se dá especialmente em razão de a "pirataria" digital ter se popularizado, mantendo-se ativa nesse período.

\section{Mobilizações sociais e o gerenciamento das normas}

O DMCA (Digital Millennium Copyright Act) é uma lei aprovada no Congresso estadunidense em 1998 a fim de regular os direitos de autor em meios eletrônicos, especialmente os que se apresentam na internet. $\mathrm{O}$ diferencial dessa lei é o seu potencial em criminalizar não somente o agente infrator do direito autoral, mas também a produção e a distribuição de meios tecnológicos que não observem a proteção da propriedade intelectual. Essa lei opera através do processo do notice and takedown, em que o material, produto ou informação sob proteção legal pode ser retirado do ar e restar indisponível mediante reclamação do suposto detentor de direitos, sem a necessidade de haver processo de escuta de defesa (Souza et al. 2014).

O processo de aprovação do DMCA foi polêmico. Dentre suas críticas estavam a possibilidade de a criminalização do acesso e a restrição ao conteúdo diminuírem o "uso justo" (em inglês "fair use") das cópias legais de materiais digitais; o possível desencadear de consequências negativas 
para a difusão do conhecimento, como a inibição da pesquisa científica e a expressão de ideias; a ameaça à limitação da capacidade de inovação e competitividade; e a restrição da liberdade na internet (Andrade et al. 2007).

Por conseguinte, algumas manifestações sociais contra tal legislação foram realizadas. Destaco as campanhas lançadas pela Fight for the Future ${ }^{7}$ - organização defensora da liberdade de expressão na internet - e pelo canal do Youtube Channel Awesome. Esses protestos se deram em 2016, quando, após muitas discussões envolvendo os mecanismos de bloqueio e de retirada do acesso através do DMCA, o U.S. Copyright Office promoveu consulta pública com o intuito de avaliar a repercussão e a eficácia da lei. Pouco antes do encerramento da consulta, a organização e o canal do Youtube em questão protestaram contra o abuso do DMCA, estimulando seus seguidores e demais cibernautas a enviar um formulário ao U.S. Copyright Office explicitando suas razões sobre por que o DMCA se mostrava abusivo e por que reformar o seu conteúdo era importante.

Mesmo se apresentando pouco antes do encerramento do prazo da consulta pública, o Fight for the Future e o Channel Awesome mobilizaram, em menos de 24 horas, aproximadamente 90.000 respostas endereçadas ao U.S. Copyright Office. Tal fluxo de protestos acabou por derrubar, por excesso de acessos, os servidores do governo (Ernesto 2016).

Para além da retirada temporária do ar de um site governamental em razão das manifestações sociais, outras formas de vivenciar, ressignificar e colonizar as expressões da lei sobre propriedade intelectual podem ser identificadas com o surgimento e a aplicação do DMCA. Uma delas se deu através de ferramenta que permitia/permite acessar e decriptar DVDs criptografados no formato CSS (Content Scrambling System) para que pudessem ser lidos em sistemas operacionais como o Linux - incapaz de ler DVDs com conteúdo protegido pela MPAA.

Por ser um meio de armazenamento de grandes quantidades de informações, o DVD, especialmente no começo dos anos 2000, passou a ser um instrumento vantajoso para os estúdios de cinema reproduzirem suas produções. As informações armazenadas em tal disco podem ser copiadas e replicadas na internet. Esta característica levou estúdios de cinema a adotarem um sistema de autenticação e criptografia chamado CSS, que visava proteger a propriedade intelectual permitindo que o disco fosse lido apenas por leitores de DVD e programas de computador licenciados (aprovados pela MPAA). No entanto, a MPAA se recusou a licenciar o CSS para sistemas operacionais como o Linux, o que desencadeou práticas de flexibilização e rearranjos das normas por usuários do Linux. 
Em 2001, Jon Johansen, um adolescente norueguês de 16 anos, desenvolveu o DeCSS, um programa capaz de decriptar o conteúdo de um DVD comercial e rodá-lo junto ao Linux. Logo após a criação do DeCSS, Jon foi levado a julgamento enquanto outros programadores publicavam o código de seu invento em sites e revistas digitais, de modo que o download do DeCSS foi realizado por centenas de pessoas. Nesse período, diversas outras ferramentas que facilitavam a decriptação de DVDs se tornaram disponíveis na internet. Como mostra a pesquisa de Eschenfelder e Desai (2004), em 2003 existiam aproximadamente 30 decriptadores para uso gratuito na internet.

Coleman (2009) observa que o caso envolvendo o DeCSS fez com que muitos cibernautas deixassem de ser meros espectadores dos feitos e do caso Johansen, tornando-se participantes em discussões que envolviam noções de liberdade de expressão e de software livre junto às controvérsias presentes na decriptação do DVD no Linux. As acusações legais contra o programador norueguês, conforme a autora, foram percebidas por muitos cibernautas como uma violação de seus direitos de usar e de produzir F/ OSS (Free and Open Source Software).

Esta perspectiva motivou um desenvolvedor a criar - com a ajuda de centenas de pessoas - e a distribuir digitalmente um software sem correlação funcional com ,o decriptador em questão nomeando-o também de DeCSS. A adoção do mesmo nome do invento de Johansen se deu para confundir agentes legais e executivos da indústria do entretenimento (Coleman 2009). Ainda conforme os estudos de Coleman, o DeCSS pode ser percebido como um caso precursor no que diz respeito aos usos do software como uma linguagem política, já que ferramentas de descriptografação são consideradas uma dentre os principais vetores de engajamento e conexão entre software livre e as noções de liberdade de expressão.

Mais do que uma linguagem política, os enredos sociotécnicos que constituem o DeCSS também promoveram colonizações - ocupações de perspectivas sobre como o acesso deveria e poderia ser junto ao DMCA. Após a notoriedade da descriptografia, inúmeros outros programas foram produzidos de modo a tornar igualitário o acesso a bens, programas, que estão em atividade até os dias atuais.

Importa saber que leis, e tentativas de criações de leis, criminalizando acessos localizados fora do circuito de aceitabilidade do mercado e do governo permearam as ações das "margens". Destaco algumas dessas regulações. A CFAA (Computer Fraud and Abuse Act), lei promulgada na década de 1980, destinada majoritariamente a atender a ameaças e a iminentes invasões a computadores governamentais (Curtiss 2016) - já que, nesse período, o acesso doméstico a computadores não era recorrente. 
Em 2011, após o evento do vazamento de vários telegramas secretos da embaixada norte-americana sobre ações militares no Oriente Médio pelo site Wikileaks, foram propostos, nos Estados Unidos, os também polêmicos projetos de lei SOPA (Stop Online Piracy Act) e PIPA (Protect IP Act), ambos com o objetivo de combater sites que distribuíssem conteúdo afrontoso às diretrizes das leis de propriedade intelectual, dificultando o acesso de internautas nos Estados Unidos a sites de conteúdo "pirata". Os projetos, além de não contarem com consulta prévia do público, nem de especialistas e de entidades que defendessem os direitos dos cibernautas, visavam conceder liberdade ao governo para este requerer a exclusão de determinadas páginas nos resultados de sites de busca.

Consequentemente, em 18 de janeiro de 2012, foram desencadeadas manifestações sociais de protesto contra os dois projetos de lei, manifestações estas que o jornal The Guardian assinalou como "o maior protesto on-line da história da internet"8 (Goodman 2012, tradução minha): diversos sites como Google, Mozilla, Reddit, I Can Has Cheezburguer (ICHC) e Wikipedia realizaram mobilizações on-line em que desativaram seus serviços, ${ }^{9}$ e/ou exibiram mensagens contra a tramitação do projeto de lei em suas páginas (Kelion 2013).

O repertório de protestos contra o SOPA e o PIPA variou, mas a mensagem passada aos usuários se mostrou uníssona em pedir aos cibernautas que agissem de modo a assinar uma petição para que o Congresso freasse os projetos.

O dia 18 de janeiro de 2012 tornou-se um dia histórico para a resistência às propostas: o Fight for the Future relatou que cerca de 75.000 sites se posicionaram contra os projetos de lei em questão; a Wikipedia apontou que 162 milhões de pessoas viram sua página em blackout; o Google confirmou que 4,5 milhões de pessoas assinaram a petição contra as propostas, e que 18 senadores estadunidenses anunciaram sua oposição aos projetos; e o Twitter relatou que foram enviados mais de 2,4 milhões de tweets mencionando os termos "SOPA" e "PIPA" em poucas horas, o que fez com que os nomes dos projetos figurassem como um dos cinco termos mais utilizados do site - termos como "SOPA", "Stop SOPA", "PIPA", e a hashtag \#factswithoutwikipedia foram os mais empregados no site (NGAK, 2012).

Outro evento relevante para essa análise envolveu Aaron Swartz, cofundador da mídia social Reddit, ativista e programador. Em 2011, Swartz foi acusado pelos Estados Unidos por fraude eletrônica (entre outras alegações) em razão de ter realizado downloads de documentos científicos e literários através da plataforma JSTOR ${ }^{10}$ (Report to the MIT'S President 2013). Promotores federais perceberam a potencialidade do caso para se 
tornar um "exemplo" para aqueles engajados ou interessados em tornar acessíveis conteúdos não autorizados, pleiteando 35 anos de prisão e multa de US\$ 1 milhão para o programador de 24 anos.

Em 2013, após 17 meses de batalhas judiciais, Swartz foi encontrado morto em seu apartamento, o que foi interpretado como suicídio. O falecimento do programador rapidamente foi associado ao rigor da condução e das punições do caso. Seu suicídio imediatamente despertou a atenção pública para a magnitude das consequências produzidas pelas disputas envolvendo leis, atores corporativos e cibernautas. As sanções legais a que estava sujeito o programador provocaram questionamentos sobre as práticas de intimidação no campo judicial, assim como a gravidade excessiva com que as violações aos direitos de propriedade intelectual foram encaradas pelo Estado.

O caso de Swartz ressalta diversas questões sobre as relações entre tecnologia, propriedade intelectual e "pirataria", como os desmedidos esforços pedagógicos praticados em defesa de direitos intelectuais; o reiterado artifício de ameaças legais destinadas àquele que produz ou se utiliza de acessos não autorizados; a percepção da informação como um bem que pode ser livre e não somente uma commodity; e o desajuste das leis em face das novas tecnologias. Esta última questão, em especial, sublinha um de meus argumentos neste artigo: o da precariedade da legibilidade em traduzir as dinâmicas tecnológicas no campo da propriedade intelectual.

Os crimes dos quais Swartz foi acusado vinculavam-se ao CFAA (Computer Fraud and Abuse Act). Com o passar do tempo, e com o advento de novos arranjos tecnológicos, a incidência do CFAA em casos informáticos passou a ser uma possibilidade mais difundida entre aqueles com acesso a computadores e rede. Apesar de algumas alterações na lei - como a inclusão de servidores privados em sua proteção -, seu conteúdo permaneceu vago e de interpretação ambivalente - características que os defensores do regulamento julgam necessárias para a segurança nacional (Curtiss 2016). Após a morte de Aaron Swartz, milhares de pessoas uniram-se em questionamentos, debates e revoltas em relação às estratégias das autoridades ao lidarem com casos envolvendo a violação dos direitos autorais no ciberespaço. ${ }^{11}$ Destaco o The Day We Fight Back, ${ }^{12}$ ocorrido em 11 de fevereiro de 2014, ocasião em que mais de 6 mil websites, em memória de Swartz, colocaram em suas páginas espaços dedicados a atacar a vigilância governamental na internet. Alguns desses espaços, visavam redirecionar seus usuários estadunidenses a entrar em contato com os membros do Congresso dos Estados Unidos, através de e-mail, ou de uma ligação pelo serviço Twilio Voice, para que requeressem das autoridades a sua oposição ao controle no ciberespaço (RT 2014). 
Outros sites também permitiam que cibernautas de outras partes do mundo tivessem acesso a uma petição de apoio aos princípios contra a vigilância em massa na web (RT 2014). Demais protestos foram planejados em diversos países do mundo ${ }^{13}$ e tomaram o formato de palestras e conversas sobre a vigilância na internet e lições sobre criptografia (The Day We Fight Back 2014).

Tentativas de alterar a CFAA após a morte de Swartz também ocorreram, e partiram tanto de agentes políticos quanto de organizações e mobilizações sociais. Em 2013, o Congresso estadunidense propôs a Aaron's Law, uma lei que visava tornar mais ponderadas as correspondências entre crime e penas. A lei não foi aprovada. Contudo, outras investidas com o objetivo de tornar o acesso mais flexível foram realizadas. Destaco o FASTR (Fair Access to Science and Technology Research Act), também chamado de "The Other Aaron's Law", que propõe que todas as agências federais que invistam mais de US\$100 milhões em subsídios para pesquisas deveriam ser obrigadas a adotar uma política de acesso aberto. A proposta está em trâmite desde 2013.

Algumas iniciativas nessa direção já acontecem. A A.B 2192 (Assembly Bill 2192) proposta pela EFF (Electronic Frontier Foundation), uma organização cujo objetivo é proteger os direitos de liberdade de expressão, apresenta um novo cenário em termos normativos: esta lei exige que qualquer trabalho acadêmico que receba financiamento do governo da Califórnia seja publicado em uma revista de acesso aberto no prazo de um ano de sua publicação. Após a lei ser aprovada por unanimidade em seu Estado, a EFF comunicou o seguinte: "A A.B. 2192 não resolve esse problema inteiramente, mas o limita"14 (Harmon 2018, tradução minha). Penso que tal mensagem comunica um processo de colonização de normas, ou seja, um processo de ocupação de novas perspectivas e objetivos para as normas que, em certo nível, a ressignifica e a modifica, incluindo interesses de grupos à "margem". Neste caso, essa colonização emergiu sobretudo em função da fatalidade da qual Swartz foi vítima.

Penso que a partir das dinâmicas dos conflitos apresentados é possível visualizar a capacidade gerenciadora não somente de programadores e usuários de "pirataria", como foi demonstrado até aqui, mas também de coletivos mobilizados. Atravessado por repertório que inclui marchas, petições on-line, ferramentas digitais de redirecionamento a sites estatais, blackouts de sites, entre outros agenciamentos, o ciberespaço congrega potencialidades de transformação social localizadas na oposição da ordem e na inscrição de seus interesses nas agendas governamentais (Schuch 2015).

Schuch (2015), ao realizar etnografia junto ao MNPR (Movimento Nacional da População de Rua), fornece importantes pistas para a compreensão da produção de legibilidade e desconstrução do Estado 
como único ator engajado em promover conjecturas nas teias estatais. A antropóloga percebeu que os esforços em tornar a "população em situação de rua" legível ao Estado (e incluída no universo da garantia dos direitos no Brasil) não se tratava de empenhos estatais somente, mas também de outros atores como organizações jurídicas e não governamentais e movimentos sociais interessados em colocar tal população nos cenários da atenção pública. ${ }^{15}$

Inspiro-me nas reflexões de Schuch (2015) para pensar a legibilidade como inscrição política, já que influências, controles e alterações nas normas - em prol da liberdade de acesso no ciberespaço - foram realizados por manifestações sociais em razão de seus interesses e criatividades

Buscando influir nos interesses políticos concernentes à liberdade de acesso, as manifestações sociais mostradas acima podem se enquadrar nas dinâmicas de celebração da construção heterogênea da legibilidade: mesmo que não visando detalhar práticas e atores "piratas" nas leis, os protestos almejavam barrar e/ou incluir novos arranjos legais que determinariam a vida e a liberdade do acesso no ciberespaço. O que quero dizer é que, similarmente às ações do MNPR, os coletivos manifestaram controle e produziram transformação nas leis (em diferentes níveis) a partir de seus interesses, a favor sobretudo da "pirataria".

O potencial comunicativo e político das tecnologias atualiza, assim, as tomadas de decisões sobre o controle ao acesso à informação, e transforma o legal em espaço habitável e em local de negociação. A interação entre instituições, discursos e práticas estatais com manifestações que se apresentam "fora" dos domínios formais permite mais do que a extensão do Estado ao cotidiano, e sim a transformação da experiência do Estado. Em um contexto marcado pelos arranjos e os embates da liberdade em oposição a expressões de controle, os cibernautas apresentam-se não apenas autorreguláveis, mas também, em certo grau, reguladores dos mecanismos de controle intentados por corporações e Estados. As tentativas de "capturar" liberdades e práticas de compartilhamento na internet desencadeiam mobilizações que apresentam o regime da propriedade intelectual como um campo constantemente imaginado, e por vezes atualizado, por agências dotadas de significados, valores e ideias heterogêneas.

As vivências e as subjetividades dos agentes que se opõem ao recrudescimento das leis em relação ao acesso produzem, através dos coletivos, seus próprios mecanismos de regulação e de atuação diante da sua emergência, modelando, habitando e regulando as normas oficiais. 


\section{“Situações de 'pirataria'” e a ilegibilidade das leis}

A "pirataria" digital representa uma situação de ilegibilidade para o Estado, que pouco sabe das potencialidades tecnológicas, dos recursos dos programadores e dos nichos de reprodução da "pirataria". Identidades, composições sociotécnicas, modos de organização e mobilizações pessoais apresentam-se pouco permeáveis às capacidades de controle estatal. Em defesa dos direitos da propriedade intelectual, as práticas "piratas" foram, e ainda são, alvos de políticas estatais e de medidas legais e pedagógicas promovidas pela indústria do entretenimento.

No entanto, em se tratando de leis de propriedade intelectual, o ilegível não é localizado somente no espaço e nas práticas "piratas": como mostrarei a seguir, os meios legalizados de distribuição de entretenimento, como os serviços de streaming, reforçam a ideia de que o Estado não é uma instituição homogênea, monolítica, envolto em uma coerência imperturbável. O que pretendo mostrar vai de encontro com tal noção. Argumento que a impossibilidade de traduzir, de ler, as práticas da população não ocorre somente no âmbito das "margens", mas também no âmbito daqueles percebidos como integrados às premissas das regulações. Em meu campo de estudo, chamarei tal configuração de "situações de 'pirataria'", ou seja: estado de ilegibilidade das normas causado sobretudo pela incapacidade (voluntária ou não) de apreensão dos sentidos da lei.

Interesso-me, neste tópico, em apresentar uma perspectiva de contraponto à participação das "margens" na produção e no controle das regulações envolvendo propriedade intelectual. Busco destacar, neste momento, as práticas de violação aos direitos autorais como parte de um repertório marginal estendido às plataformas de streaming localizadas no universo legalizado. Enfatizo as narrativas de tais serviços em que essas violações são possibilitadas pela ininteligibilidade e/ou dificuldade de observação da norma.

A relevante quantidade de acusações e condenações que os serviços de streaming analisados enfrentaram, e ainda enfrentam, no que se refere à violação de direitos autorais inspirou-me a abordar narrativas que salientam as irracionalidades internas do Estado.

Essas incidências indicam não somente os riscos que os mercados acatam em seus empreendimentos, mas revelam também a ilegibilidade localizada e produzida "a partir" da lei. É interessante perceber como os discursos "antipirataria", fundamentados no respeito aos direitos autorais e na valorização do trabalho dos artistas, coexistem com as infrações a esses mesmos direitos. 
Assim, analiso aqui as controvérsias que permeiam as ilegibilidades dos serviços junto ao Estado. O intuito é demonstrar como, mesmo com as vastas regulações e campanhas que visavam/visam combater a "pirataria", a distribuição legal do entretenimento é percebida inobservante, "fora" dos protocolos do regime de propriedade intelectual, criando zonas que chamo de "situações de 'pirataria'".

Para tal abordagem utilizo como suporte teórico sobre legibilidade os pensamentos de James Scott (1998) e de Durão (2009). Estes autores auxiliam a pensar a maleabilidade e a incompletude das leis, assim como a produção e a habitação do repertório marginal nelas.

A incompleta, ou por vezes nula, absorção do Estado sobre o conhecimento das práticas e das situações dos sujeitos é abordada por mim através do conceito de "legibilidade" de Scott (1998). Este conceito, brevemente apresentado na introdução, atravessa a constituição do Estado Moderno enquanto um conjunto de instrumentos de controle da população. Conhecer os sujeitos, suas localizações, suas atividades consiste em ações de monitoramento importantes para a capacidade estatal de intervir com políticas públicas e outras medidas que visem fiscalizar, administrar, limitar, dominar e controlar populações. Assim, o termo "ilegibilidade" se relaciona com o que dificilmente pode ser traduzido pelo Estado. Remete ao que não é assimilado pelo aparato de controle.

Paralelamente, as contribuições de Durão (2009) - que também trabalha com o termo "legibilidade" de Scott (1998) - sublinham as ilegibilidades do Estado como atuantes não somente em suas "margens", mas também no centro. Ou seja, em seus mecanismos produtores de ordem. Em etnografia realizada junto a policiais portugueses, Durão (2009) analisa as dinâmicas, atividades e discursos que atravessam as atividades policiais como produtoras de contextos de centro e margem no âmago do próprio Estado.

Durão (2009) demonstra em seu trabalho ambivalências na formação de modelos de policiamento. Apresenta imprecisões (e frustrações) sobre os capitais simbólicos que envolvem o fazer policial, e hesitações no entendimento dessas atuações pelos agentes. Tais indeterminações se localizam tanto nas emoções e nas percepções dos policiais sobre seus trabalhos quanto no entendimento da produção e da interpretação da ordem, refletindo, como sugere a autora, em ilegibilidades produzidas pelo Estado que incidem sobre sua própria funcionalidade e racionalidade. Assim, as incertezas e as insatisfações sobre os entendimentos do trabalho policial pelos próprios policiais estudados acabavam gerando ilegibilidades e irracionalidades internas ao Estado. 
O trabalho de Durão (2009) contribui para pensar as incongruências e as dificuldades percebidas por atores que integram códigos e protocolos estatais, e que se apresentam como conformadores destes. Refletindo sobre o papel das plataformas nas relações entre "pirataria" e leis, e realizando uma analogia com a atuação da polícia a partir da perspectiva de Durão (2009), é possível associar os serviços de streaming a dispositivos de produção de ordem.

Assim como a polícia, essas plataformas também se constituem como mecanismos de controle de comportamento (e legalidade), não através do monopólio do uso da força, mas sim de seus discursos e estratégias fundamentados sobretudo em apelos "antipirataria", muitas vezes amparados pelo Estado. Os serviços de streaming representam, na atualidade, os principais meios que convergem para e que animam acessos legais e observação aos direitos de propriedade intelectual: são canais de expressão e de prática da ordem.

Interpretando-os como uma manifestação dos centros - revelações da ordem - as plataformas - assim como as atividades policiais analisadas por Durão (2009) -, são permeadas pela ininteligibilidade das leis de propriedade intelectual: de acordo com as narrativas dos serviços, o sentido dessas regulações não é apreendido ou acessado facilmente, tornando-os, muitas vezes, ilegíveis aos que disponibilizam conteúdo em tais canais.

A ininteligibilidade (e a ilegibilidade) promove certa correspondência com a negligência "pirata" em face das leis, tomando o Estado como mais um agente revelador de sua própria contradição (Das \& Poole 2004).

Para compreender as ilegibilidades que circundam os serviços audiovisuais de streaming, abordarei dois fenômenos: os "direitos mecânicos" presentes nos serviços de áudio; e a produção da própria propriedade intelectual por serviços de vídeo.

No curso desta pesquisa, estes dois fenômenos expressaram ilegibilidades a partir de e dentro do legal, mostrando-se contumazes e polêmicos para o público que, por vezes, questionava a integridade das plataformas como meios honestos de distribuição do entretenimento e, outras vezes, as aproximava da "pirataria". Saliento que a ininteligibilidade das normas constitui os discursos dos próprios serviços, e que não objetivo apontar verdades sobre tais comunicações, mas sim problematizar sua construção e sua existência no debate sobre Estado/"margens" e legibilidade/ilegibilidade. 


\section{Direitos mecânicos: quem/o que é ilegível?}

Os direitos mecânicos compõem uma das diversas camadas da regulação da propriedade intelectual. Referem-se à garantia legal endereçada a compositores e produtores por suas criações musicais. A estes artistas cabe tanto o reconhecimento autoral quanto o recebimento pecuniário pelas transmissões que tecnologias de reprodução realizam. Contudo, tal processo de cumprimento legal encontra obstáculos junto às plataformas de streaming .

As dificuldades em alcançar/atingir e mesmo enxergar os requisitos de cumprimento dos direitos de propriedade intelectual na vida prática dos serviços de streaming são uma recorrente nos discursos do campo musical. A distribuição ilegal de canções pelas plataformas apresenta-se, na atualidade, sob suspeitas de duas ordens: i) a inobservância intencional dos direitos intelectuais por parte dos serviços e; ii) a dificuldade das plataformas em atenderem à lei.

A onipresença da (violação) regulação da propriedade intelectual tem se mostrado um obstáculo para os canais de streaming que se estabeleceram no mercado legalmente - muitos se respaldando no discurso de combate à pirataria - minando, muitas vezes, as percepções de fronteiras entre plataformas legais e ilegais. Intencionalmente ou não, a ilegibilidade praticada acaba por sugerir uma constante inadequação dos atores às responsabilidades decorrentes da lei, além de inspirar o retorno do público às noções de ganância referentes à indústria, e suscitar uma atmosfera de hipocrisia para aqueles que fundamentaram seu exercício na valorização do artista e na disputa com a "pirataria".

Nos últimos cinco anos, serviços de streaming de música como Rhapsody, Google Play Music, Microsoft-Groove Music, Spotify, Slacker Radio e Tidal foram acusados de violação dos chamados "mechanical rights" (direitos mecânicos), direitos que preveem o pagamento de royalties aos compositores toda vez que cópias de suas músicas são reproduzidas no modo digital.

Toda gravação tem dois direitos autorais: um pela gravação do áudio e outro pela composição. Muitos dos distribuidores dos quais os serviços de streaming obtêm as músicas de seus catálogos recebem o pagamento de royalties somente pela gravação da música, e não por sua composição, devendo as plataformas obter uma licença para o seu uso.

De acordo com o presidente e CEO da NMPA (National Music Publishers Association), Davide Israelite, a falha em obter os licenciamentos devidos e/ou compensar satisfatoriamente e de forma justa os compositores é uma questão que domina cerca de $25 \%$ dos serviços de streaming (legais) 
na atualidade. Nestes casos, os direitos mecânicos não são pagos aos compositores, ou estão sendo distribuídos equivocadamente para entidades que não fazem parte da rede dos direitos autorais.

Essas violações decorrem, de acordo com manifestações de representantes das plataformas e de organizações que defendem os interesses de artistas e gravadoras, de múltiplos fatores, dentre eles, o tratamento da autoria em países como os Estados Unidos e sua descentralização nos modos de licenciar as canções, ${ }^{16}$ e as limitações (tecnológicas, éticas, gerenciais) dos serviços de streaming em contemplar, de modo completo, o cumprimento de todos os nós das leis da propriedade intelectual.

\section{Compondo ilegibilidades}

Com a polêmica das quantias destinadas aos artistas através dos serviços de streaming, e com o sentimento de indignação diante do tratamento de desvalorização do trabalho dos músicos, surge, em 2014, a plataforma Tidal. Diferentemente dos serviços operantes, o Tidal fundamenta sua atividade não no combate à "pirataria", mas no combate à depreciação do trabalho artístico de cantores e cantoras - relacionada, também, às possibilidades de as músicas serem ouvidas "gratuitamente" em algumas plataformas.

A partir desta postura, o canal foi (auto)anunciado como "artistfriendly", ou seja, benéfico ao artista. O serviço também se diferencia por ser gerenciado por artistas de grande relevo na indústria do entretenimento, como Jay-Z, Beyoncé, Arcade Fire, Madonna, entre outros. Apesar disso e dos discursos que destacam vantagens a estes e aos e criadores de música, o Tidal (assim como outros serviços de streaming) envolveu-se em litígios judiciais concernentes à distribuição de royalties.

Em 2016 a gravadora Yesh Music Publishing e o artista John Emanuele ajuizaram uma ação de US\$ 5 milhões contra a plataforma alegando que ela licenciara pelo menos 118 músicas sem a permissão do artista, além de não pagar os devidos royalties de transmissão (Geigner 2016; Kokalitcheva 2016). De acordo com o discurso proferido judicialmente pela gravadora e por John Emanuele, o serviço elaborou um "plano de negócios calculado para evitar os custos associados ao cumprimento adequado de $\mathrm{NOI}^{\prime}{ }^{17}{ }^{17} \mathrm{e}$ para reter royalties para os quais eles não têm direito"18 (USA - Yesh Music vs. S. Carter Enterprises 2016, tradução minha). Em declaração à mídia, o Tidal se manifestou no sentido de que os requerentes estão "mal informados" sobre quem lhes deve os royalties (Lockett 2016). 
Também situada em contexto fluido, em que direitos, deveres e (i) legibilidades disputam e compõem os limites do Estado e da distribuição do entretenimento, a versão legalizada do Napster - um dos mais populares programas de compartilhamento de arquivos "piratas" do início dos anos 2000 - também enfrenta ações judiciais relativas ao descumprimento dos direitos mecânicos. Uma das mais antigas empresas atuantes no cenário musical digital (desde 2001), o Napster foi acusado judicialmente pelo cantor e compositor David Lowery, juntamente com os compositores Victor Krummenacher e David Faragher, por descumprir as formalidades da licença dos direitos mecânicos nos Estados Unidos (Beethovan 2016).

No processo judicial que contempla a contenda é possível identificar acusações de negligência na observação dos direitos de propriedade intelectual, e intencionalidade das violações dos direitos mecânicos. Para os compositores, a plataforma não se esforçou em localizar as pessoas detentoras de direitos mecânicos. De acordo com excerto do litígio:

O Rhapsody reproduz e/ou distribui as obras, apesar de sua falha em identificar e/ou localizar os proprietários dessas composições para pagamento, ou para avisá-los da intenção do Rhapsody de reproduzir e/ou distribuir as obras. [...] A violação dos direitos mecânicos pelo Rhapsody é consciente e intencional. O Rhapsody tem continuamente falhado em usar qualquer um dos muitos mecanismos disponíveis para obter a autorização adequada para a reprodução e/ou a distribuição da obra, seja na forma de uma licença voluntária ou compulsória, e se o titular do direito é facilmente identificável ou não (USA Court - Lowery vs Rhapsody 2016, tradução minha). ${ }^{19}$

Desleixo, displicência e descaso, noções que compõem acusações em esfera judicial contra as plataformas, manifestam as contradições de lidar com a lei no âmbito legal. A partir de tais exemplos, é possível pensar o descumprimento da lei não somente como intencional, mas também como provocado pela ininteligibilidade dos nós que compõem o regime de propriedade intelectual.

Com tal pensamento não busco justificar ilegalidades, mas sugerir que as leis, a partir das narrativas dos detentores e interessados nos direitos mecânicos, podem não ser inteligíveis, acessíveis ou racionais em suas lógicas.

As ameaças à legibilidade das plataformas também podem ser visualizadas na trajetória do Spotify, que atualmente se apresenta como o canal de streaming que mais prolifera polêmicas envolvendo o cumprimento do pagamento de royalties e observação dos direitos mecânicos. 
Tais polêmicas, conforme a própria plataforma, decorrem das dificuldades em localizar os detentores desses direitos, especialmente os compositores.

Em 2015 declarações e ações judiciais foram acionadas contra o serviço alegando descumprimento da observação dos direitos em questão. O músico David Lowery e outros músicos apresentaram uma ação coletiva contra o Spotify. Em 2016 a compositora Melissa Ferrick processou a empresa pelo não pagamento dos devidos royalties. Em 2017 o compositor Bob Gaudio e a Bluewater Music Services Corporation acusaram a plataforma de violação de direitos autorais, deslegitimando a capacidade do serviço em se adaptar às premissas legais, e questionando suas práticas e ética nos negócios.

De acordo com o serviço, tal situação corresponde a uma lacuna na gestão de negócios, já que os dados que permitem o cumprimento dos direitos autorais pelo serviço - dados que localizam os detentores dos direitos geralmente se apresentam incompletos, ausentes ou errados:

Um dos nossos principais compromissos é garantir que todos os envolvidos na criação de música sejam pagos de forma justa, rápida e transparente. Infelizmente, quando se trata de royalties de publicação e composição, especialmente nos Estados Unidos, é mais fácil falar do que fazer, porque os dados necessários para confirmar o detentor dos direitos apropriados geralmente estão ausentes, errados ou incompletos (Spotify 2015, tradução minha). ${ }^{20}$

Conforme a plataforma, em muitos casos, a dificuldade em reconhecer o direito autoral ocorre devido às seguintes razões: a propriedade dos direitos não se encontra finalizada quando o registro é liberado; os direitos são detidos por várias partes; ou os direitos mudam de detentores dificultando encontrar ou acompanhar seus novos titulares (Spotify 2015). O Spotify também argumenta que, quando um ouvinte estadunidense executa uma faixa na qual o titular dos direitos não está definido, a plataforma retém os royalties devidos até que possam identificar quem é o titular dos direitos autorais (Spotify 2015).

A relação do Spotify com a propriedade intelectual, envolvida por controvérsias e reveses, levou o serviço a investir, em março de 2017, na Sonalytic, uma empresa que desenvolve tecnologias de deteç̧ão de áudio capaz de rastrear conteúdo protegido por direitos autorais. Em abril do mesmo ano, a plataforma investiu na aquisição da startup Mediachain Labs, responsável por um sistema operado através da tecnologia blockchain, que registra, identifica e rastreia trabalhos criativos on-line possibilitando que criadores anexem informações de suas criações, e que o público identifique quem é o autor e quem detém os direitos de autor (Canaltech 2017). 
Apesar dos esforços em se manter legal, o serviço ficou sem atender às condições do regime de propriedade intelectual: em julho de 2017 - dois meses após a aquisição da Mediachain Lab -, o Spotify foi processado por violar os direitos autorais de 2,5 mil canções que supostamente estariam disponíveis em seu serviço sem licenciamento apropriado (Rau 2017).

As repetidas inobservâncias da lei conduziram usuários, bloggers, jornalistas e compositores a litigar contra o Spotify, a estabelecer correspondências entre tais plataformas e as atividades do Napster de 1999-2001, e também com os demais programas de compartilhamento considerados ilegais. As ações movidas contra essas plataformas se assemelham, protagonizando a reprodução e a distribuição indevida de trabalhos autorais e a falta de repasse dos royalties cabidos.

Os serviços de streaming, independentemente de suas razões em face dos direitos autorais - se não querem ou não conseguem respeitar as premissas das leis -, integram os direitos intelectuais, ao mesmo passo em que escapam deles, evidenciando-os como um problema no mercado. "Escapar" e ser "escapado" (voluntariamente ou não) configura uma constante até o momento nas atividades dos serviços de distribuição digital que venho pesquisando.

Com base nos breves exemplos apontados acima, percebemos que o "mapa abreviado" formulado pelo Estado, ou seja, as regulações que visam padronizar os usos e os acessos a bens intelectuais, são constantemente desviados pelas plataformas. Estas, apesar de comporem a dimensão legal, ultrapassam os limites da norma desencadeando ilegibilidades - isto é, o não conhecimento das atividades dos sujeitos - "a partir" e "dentro" da lei, fazendo-nos questionar o que "escapa": a lei ou o serviço? Penso que essa divergência pode ser explicada pelas inovações técnicas, pelo conservadorismo das regulações da propriedade intelectual, assim como pelas práticas e a criatividade de habitar a lei, e de negociar legibilidades.

\section{Considerações finais}

Neste artigo busquei abordar os diferentes movimentos que a "pirataria" e os serviços de streaming realizam em suas interações com as leis de propriedade intelectual. Quis enfatizar, sobretudo, que noções, moralidades, práticas e movimentos sociais atrelados às questões "piratas" têm capacidade de agir sobre a lei, por vezes limitando-a, parando-a, atualizando-a, colonizando-a. Trata-se de uma capacidade que as "margens" dispõem em determinados contextos (Das \& Poole 2004), e que reflete parte das práticas envolvendo a "pirataria". 
De mesmo modo, busquei destacar que o ilegível, o que não é passível de apreensão/absorção/entendimento/leitura pelo Estado, também pode se localizar junto aos agentes que baseiam sua razão de ser na legalidade. $\mathrm{Na}$ dinâmica de não comprenderem regras e de se localizarem fora do campo de (super)visão do Estado, as plataformas de streaming apresentam violações de direitos autorais, sugerindo que a ilegibilidade permeia não somente a "margem", mas também caracteriza um segmento do mercado e da indústria do entretenimento.

Assim, ao mesmo passo em que o Estado é moldado pela agência "pirata", os serviços de streaming atuam como ilegíveis, violando, muitas vezes, o conjunto de direitos que mais destacam como protetores.

Recebido em 04 de setembro de 2019

Aprovado em 13 de outubro de 2020

Andressa Nunes Soilo

É doutora e mestra em Antropologia Social pela Universidade Federal do Rio Grande do Sul (UFRGS), cientista social graduada pela mesma universidade e bacharel em Direito graduada pelo Centro Universitário Ritter dos Reis (UNIRITTER). Pesquisa temas nas áreas da Antropologia da Propriedade Intelectual, Antropologia Digital e Antropologia do Consumo.

https://orcid.org/0000-0002-0314-1568

E-mail: andressansoilo@outlook.com 


\section{Notas}

1 Estes também foram analisados por mim a partir de suas operacionalidades, sociabilidades, características sociotécnicas, manifestações formais em documentos e/ou discursos de seus representantes, além de sites de notícia, blogs, e minhas próprias experimentações técnicas junto a tais plataformas.

2 A url corresponde à identificação de recursos a serem acessados pelos agentes em rede, fornecendo o endereço/caminho para que haja a interação dos atores com os recursos desejados.

3 Inicialmente eu não procurava, em sites buscadores, por crimes potencialmente cometidos pelos serviços em questão, mas a mera digitação de seus nomes nos sites elencava-os para mim.

4 Ao final da Idade Média, a exploração comercial do conhecimento e a necessidade de manutenção de segredos técnicos mobilizaram a ascensão da propriedade intelectual enquanto marco regulatório que equiparava bens imateriais a bens materiais a fim de possibilitar a proteção de novas ideias. Desde suas primeiras expressões no Ocidente, a propriedade intelectual foi justificada - especialmente a partir do século XVIII - pelo discurso político fundamentado no bem social, assim como no progresso social, já que as invenções passaram a ser percebidas enquanto artefatos capazes de promover benefícios à sociedade (Burke 2003).

5 Bens que não têm sua quantidade reduzida independentemente de seu consumo.

6 Um dos mais conhecidos instrumentos de legibilidade (e controle) referente à aplicação de leis de propriedade intelectual em nível global é o Special 301. Ele consiste em relatório anual formulado pelo Office of the US Trade Representative (USTR), que classifica, desde o final da década de 1980, países em diferentes níveis de observação quanto à proteção e à aplicação dos direitos da propriedade intelectual, realizando sugestões sobre o tema às nações analisadas, e aplicando sanções casos os países não observem os acordos firmados.

7 "Fight for the Future" é uma organização sem fins lucrativos, fundada em 2011, que objetiva garantir a liberdade de expressão e a criatividade na internet (Fight for the Future 2016).

8 Originalmente: "The largest online protest in the history of the internet" (Goodman 2012).

9 Sites como Reddit, Boing Boing e Tucows removeram os acessos a seu conteúdo (Kelion 2012).

10 JSTOR é uma editora on-line que digitaliza artigos e os vende na internet.

11 Particularmente, a história de Swartz também me sensibilizou e me aproximou dos conflitos que atravessam meu campo de estudo. Durante minha 
trajetória acadêmica, foram incontáveis as ocasiões em que me deparei com as restrições da plataforma JSTOR em disponibilizar acesso a obras necessárias para minhas pesquisas.

12 O site oficial desse protesto on-line (https://thedaywefightback.org/) apresenta recortes de notícias publicadas em diversos jornais de grande circulação do mundo envolvendo a vigilância de agências de inteligência na internet, assim como um vídeo sobre a importância de combate à invasão da privacidade na internet, e sugestões de como atuar em prol da liberdade na internet.

13 Países como Colômbia, Costa Rica, Canadá, Brasil, Dinamarca, Índia, Irlanda, Alemanha, Sérvia, África do Sul, Suécia, Reino Unido, Estados Unidos e Áustria fizeram parte do The Day We Fight Back (The Day We Fight Back 2014).

14 Citação original: "A.B. 2192 doesn't solve that problem entirely, but it does limit it" (Harmon 2018).

15 Alguns exemplos dessa "via de mão dupla" em termos de produção e de celebração da legibilidade podem ser percebidos nos seguintes exemplos: na publicação de cartilhas que pedagogicamente informam direitos da população de rua; normativas legais sobre a proteção de tal grupo; e a realização da primeira contagem nacional realizada em 2007 (Schuch 2015).

16 Diferentemente de outros países, os Estados Unidos não possuem uma organização centralizada de licenciamento coletivo que represente nacionalmente os autores das músicas (Bezilla 2017).

17 NOI é a sigla para Notice of Intent que, de acordo com a lei estadunidense, deve ser enviada aos compositores detentores de direitos mecânicos, ou então, em caso de titular indeterminado, o NOI deve ser enviado ao escritório de direitos autorais dos Estados Unidos.

18 Citação original: "Calculated business plan to avoid the costs associated with properly serving NOI's, and to retain royalties for which they have no right" (USA - Yesh Music vs S Carter Enterprises 2016).

19 Citação original: "Rhapsody reproduces and/or distributes the works despite its failure to identify and/or locate the owners of those compositions for payment, or to provide them with notice Rhapsody's intent to reproduce and/or distribute the works. [...] Rhapsody's infringement of mechanical rights is knowing and willful. Rhapsody has continoulsy failed to use any one of the many available mechanisms to properly obtain authorization for the reproduction and/or distribution of the work, wheter in the form of a voluntary or compulsory license, and wheter or not the rightholder is readily identifiable." (USA Court - Lowery vs Rhapsody 2016).

20 Citação original: "One of our core commitments is making sure that everyone involved in the creation of music is paid fairly, rapidly, and transparently. Unfortunately, when it comes to publishing and songwriting royalties, especially in the United States, that's easier said than done because the data necessary to confirm the appropriate rightsholder is often missing, wrong, or incomplete." (Spotify 2015). 


\section{Referências bibliográficas}

BEZILLA, Paul. 2017. Bob Gaudio Tells Spotify To Walk Like a Man. In: Pay or Play. Disponível em: <https:// payorplay.foxrothschild.com/2017/07/ articles/music/bob-gaudio-tellsspotify-to-walk-like-a-man/> . Acesso em 13/01/2018.

BURKE, Peter. 2003. Uma História Social Do Conhecimento I. De Gutenberg a Diderot. Rio de Janeiro: Zahar, 2003.

CANALTECH, 2017. Spotify compra empresa para identificar dono dos direitos autorais de uma música. In.: Canaltech. Disponível em: < https:// canaltech.com.br/mercado/spotifycompra-empresa-para-identificardono-dos-direitos-autorais-deuma-musica-92816/>. Acesso em 04/09/2019.

DAS, Veena \& POOLE, Deborah (eds.). 2004. Anthropology in the margins of the State. Santa Fe: School of American Research Press.

DURÃO, Susana. 2009. Os olhos da sociedade... Uma etnografia nas esquadras de polícia de Lisboa. Intersecções, v. 11, n. 1:9-33. Disponível em: <http://repositorio. ul.pt/bitstream/10451/11097/1/ICS_ SDurao_Olhos_ARI.pdf $>$.Acesso em 10/01/2018.

FIGHT FOR THE FUTURE. 2016. Disponível em: <https://www. fightforthefuture.org/ $>$. Acesso em 04/09/2019.

GIBLIN, Rebecca. 2018. A New Copyright Bargain? Reclaiming Lost Culture and Getting Authors Paid. Columbia Journal of Law \& the arts, v. 41:369-411. Disponível em: <https://papers.ssrn.com/sol3/ papers.cfm?abstract_id $=3252838>$. Acesso em 23/10/2018.
GOODMAN, Amy. 2012. The Sopa blackout protest makes history. The Guardian. Disponível em: <https://www.theguardian.com/ commentisfree/cifamerica/ 2012/ jan/18/sopa-blackout-protest-makeshistory >. Acesso em 04/09/2019.

KELION, Leo. 2013. Netflix studies piracy sites to decide what to buy. $B B C$ News. Disponível em: http://www. bbc.com/news/technology-24108673. Acesso em 20/04/2017.

LEAL, Ondina Fachel \& SOUZA, Rebeca Hennemann Vergara de. 2010. Do regime de propriedade intelectual Estudos antropológicos. Porto Alegre: Tomo Editorial, 2010.

LEAL, Ondina Fachel; SOUZA, Rebeca Hennemann Vergara de \& SOLAGNA, Fabrício. 2014. Global Ruling. Intellectual Property and Development in the United Nations Knowledge Economy. Vibrant, Brasília, v. 11, n. 2. Disponível em: http://www.scielo.br/scielo. php? script $=$ sci_arttext $\&$ pid $=$ S 1809 -43412014000200004. Acesso em 19/11/2018.

LOCKETT, Dee. 2016. Tidal Is Being Sued for the One Thing Jay Z Said It Wouldn't Do: Not Paying Artists. Vulture. Disponível em: https://www. vulture.com/2016/02/tidal-sued-forallegedly-not-paying-artists.html. Acesso em 05/01/2018.

MACHADO, Jorge. 2010. Desconstruindo "Propriedade Intelectual". Cadernos GPOPAIG, 2, São Paulo, POPAI-USP. Disponível em: < http://obs.obercom. pt/index.php/obs/article/view/92>. Acesso em 22/10/2018.

RAU, Nate. 2017. Spotify Illegally Streaming Songs by Miranda Lambert, Willie Nelson and more, Lawsuits Say. 
Tennessean, 18 jul. Disponível em: http://www.tennessean.com/story/ money/2017/07/18/spotify-suednashville-publishers-not-properlylicensing-songs/485999001/. Acesso em 25/07/2017.

SCHUCH, Patrice. 2015. "A legibilidade como gestao e inscrição política de populações: notas etnográficas sobre a política para pessoas em situação de rua no Brasil". In: Claudia Fonseca \& Helena Machado (orgs.), Ciência, identificação e tecnologias de governo. Porto Alegre: EDUFRGS/ CEGOV. pp. 121-145.

SCOTT, James. 1998. Seeing like State: how certain schemes to improve the human condition have failed. Nova Haven: Yale University Press.

SELL, Susan \& MAY, Christopher. 2001. Moments in law: contestation and settlement in the history of intellectual property. Review of International Political Economy, 8 (3):467-500.
SPOTIFY. 2015. Spotify Songwriters and Publishers Administration System. Disponível em: < https://artists.spotify. com/blog/spotify-songwriters-andpublishers-administration-system $>$. Acesso em 13/10/2017.

STRATHERN, Marylin. 1999. No limite de uma certa linguagem. Mana, Rio de Janeiro, v. 5, n. 2:157-175, out. Disponível em: <http://www.scielo.br/scielo. php? script $=$ sci_arttext $\&$ pid $=$ S0104 -93131999000200007>. Acesso em 04/08/2019.

USA COURT - GAUDIO vs SPOTIFY. 2016. Defendant's memorandum in support of motion for a more definite statement - In the United States District Court for the Middle District of Tennessee Nashville division. Case $n^{\circ}$ 3:17-cv-01052. Disponível em: https://www.documentcloud. org/documents/3984641-GaudioSpotifyMotion.html.Acesso em 20/02/2019. 
HABITANDO A LEI: "PIRATARIA", STREAMING, E O REGIME DE PROPRIEDADE INTELECTUAL

\section{Resumo}

Este artigo aborda as leis de propriedade intelectual como um conjunto de regulações constituído por relações porosas estabelecidas entre o legal/ ilegal. Para além de uma configuração permeada por normas e comportamentos alinhados a uma racionalidade jurídica, argumento que as regras envolvendo a propriedade das criações do intelecto são atravessadas, interditadas, moldadas, editadas e criadas a partir de negociações com agentes situados em campos em que o legal e o ilegal estão interrelacionados. Analiso este modo de habitar, ou seja, colonizar, ressignificar as leis de propriedade intelectual, a partir de meu estudo etnográfico junto às plataformas de streaming (de vídeo e música) e à "pirataria" digital, em que identifico a permeabilidade dos campos legal/ ilegal não apenas na constituição da lei, mas também nas experiências de atores "piratas" e operadores de serviços legais.

Palavras-chave: Pirataria, Propriedade intelectual, Margens, Legibilidade.

\author{
OCCUPYING THE LAW: "PIRACY", \\ STREAM ING, AND INTELLECTUAL \\ PROPERTY RIGHTS
}

\section{Abstract}

This article addresses intellectual property laws as a set of regulations made up of porous relations between legal and illegal categories. In addition to a configuration permeated by behaviors and norms linked to a legal rationality, I argue that the rules involving the ownership of the creations of the intellect are crossed, interdicted, molded, edited and transformed from negotiations with agents located in fields where the legal and the illegal are interrelated. I analyze ways that intellectual property laws are colonized and resignified through my ethnographic study with (video and music) streaming platforms and digital "piracy", in which I identify the permeability of legal /illegal fields, not only in the constitution of the law, but also in the experiences of "pirate" actors and operators of legal services.

Keywords: piracy; intellectual property; margins; legibility. 


\section{HABITANDO LA LEY: "PIRATERÍA”, STREAMING Y EL RÉGIM EN DE PROPIEDAD INTELECTUAL}

\section{Resumen}

Este artículo aborda las leyes de propiedad intelectual como un conjunto de regulaciones compuestas por relaciones porosas entre las categorías legales e ilegales. Además de una configuración permeada por comportamientos y normas vinculadas a una racionalidad jurídica, sostengo en este artículo, que las reglas que involucran la propiedad de las creaciones de intelecto se cruzan, interceptan, moldean, editan y transforman a partir de negociaciones entre agentes ubicados en campos donde lo legal y lo ilegal están interrelacionados. Analizo este modo de colonizar y resignificar las leyes de propiedad intelectual a partir de mi estudio etnográfico con plataformas de streaming (video y música) y con la "piratería" digital, en las cuales identifico la permeabilidad de los campos legales e ilegales, no solo en la constitución de la ley, sino también en las experiencias de actores "piratas" y operadores de servicios legales.

Palabras clave: piratería; propiedad intelectual; márgenes; legibilidad. 